\title{
P-1098 Mental distress and health-related QOL among patients with diabetes using SMBG in Japan: a large-scale survey
}

\section{${ }^{1,2}$ Nagaaki Tanaka, ${ }^{1}$ Daisuke Yabe, ${ }^{1,2}$ Yutaka Seino and Positive SMBG study group}

${ }^{1}$ Yutaka Seino Distinguished Center for Diabetes Research, Kansai Electric Power Medical Research Institute, Kobe, Japan; ${ }^{2}$ Center for Diabetes, Endocrinology and Metabolism, Kansai Electric Power Hospital, Osaka, Japan

\section{Background and Aims}

Although self-monitoring of blood glucose (SMBG) is established as a useful tool for self management for patients with type 1 diabetes (T1D) and type 2 diabetes (T2D), mental distress associated with SMBG has remained unsolved. The aim of the present study was to explore whether views of patients with diabetes toward selfmonitoring of blood glucose (SMBG) and involvement of their doctors affect the patients' quality of life (QOL).

\begin{tabular}{|c|c|c|}
\hline \multicolumn{2}{|c|}{$\begin{array}{c}\text { Characteristics of the study } \\
\text { participants }\end{array}$} & \multirow[b]{2}{*}{ T2D } \\
\hline & T1D & \\
\hline n (male/female) & $\begin{array}{r}517 \\
(234 / 282)\end{array}$ & $\begin{array}{r}1648 \\
(982 / 659)\end{array}$ \\
\hline Age (years) & $51.4 \pm 15.7$ & $64.1 \pm 11.6$ \\
\hline BMI $\left(\mathbf{k g} / \mathbf{m}^{2}\right)$ & $22.9 \pm 3.5$ & $25.4 \pm 4.5$ \\
\hline Duration of diabetes (years) & $15.2 \pm 10.6$ & $16.8 \pm 10.0$ \\
\hline Duration of insulin use (years) & $14.0 \pm 10.4$ & $8.0 \pm 6.7$ \\
\hline HbA1c (\%) & $7.8 \pm 1.2$ & $7.5 \pm 1.1$ \\
\hline $\begin{array}{l}\text { Frequency of SMBG instructed by } \\
\text { doctors (times/day) }\end{array}$ & $3.2 \pm 1.2$ & $2.2 \pm 1.1$ \\
\hline \multirow[t]{2}{*}{$\begin{array}{l}\text { Frequency of SMBG performed by } \\
\text { patients (times/day) }\end{array}$} & $3.4 \pm 1.8$ & $2.4 \pm 1.6$ \\
\hline & \multicolumn{2}{|c|}{$($ mean $\pm \mathrm{SD})$} \\
\hline
\end{tabular}

\section{Factors associated with SMBG-} associated distress

T1D and T2D patients who answered "very unlikely" and "unlikely" (A) and "likely and "very likely" (B) to Q2 "How painful is SMBG to you?"
A. TMD T-score

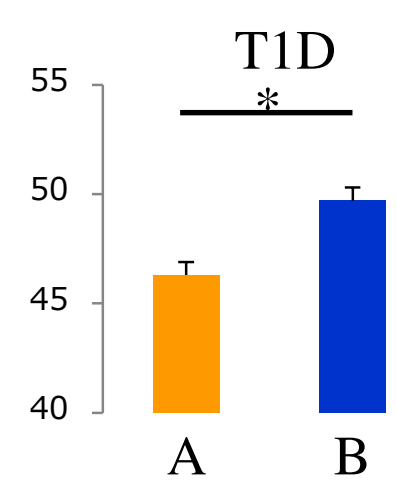

C. HbA1c T1D

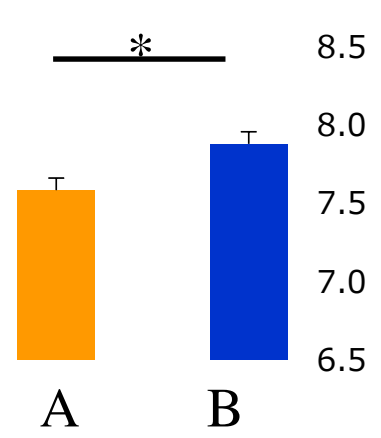

\section{B. DTR-QOL total score}

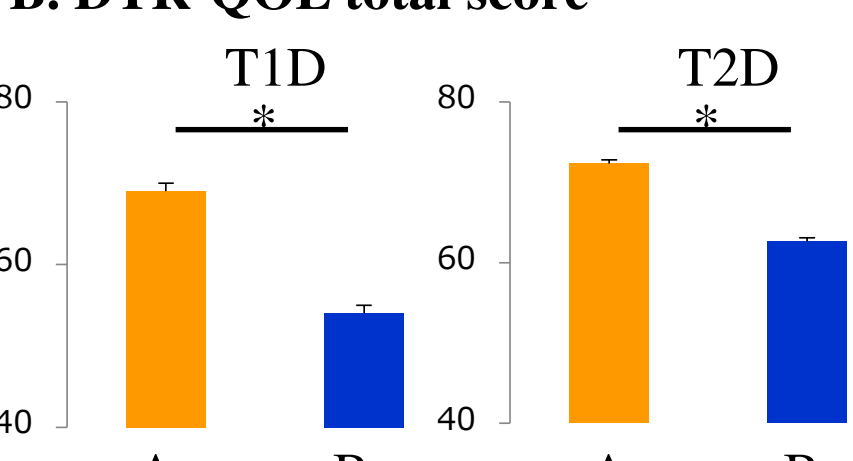

A

D. Frequency of SMBG testing

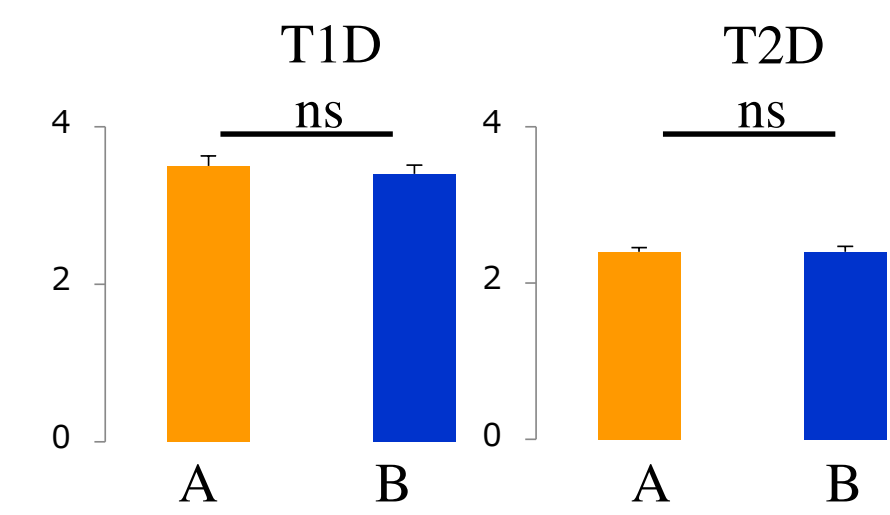

Data are shown as mean \pm SEM. * indicates $P<0.05$.

TMD T-score; total mood disturbance score calculated by POMS2.

\section{Conclusion}

T1D and T2D experiencing SMBG-associated discomfort had more mental distress, lower health-related QOL and higher $\mathrm{HbAlc}$, regardless of daily SMBG checks. Doctors' involvement with SMBG education might reduce the SMBG-related distress and increase the health-related QOL.

\section{Materials and Methods}

This multi-center, cross-sectional survey was conducted in patients with type 1 (T1D) and type 2 (T2D) diabetes using SMBG, recruited from 42 Japanese medical institutions. To evaluate mood status and health-related QOL, Profiles of Mood States 2 (POMS2) and diabetes therapy-related QOL (DTR-QOL) were used. An original questionnaire was developed asking how SMBG gave Q1) "importance" Q2) "painfulness" and Q3) "confidence" to the patients. Another questionnaire for doctors was also developed including how often they checked SMBG diary (QD4).

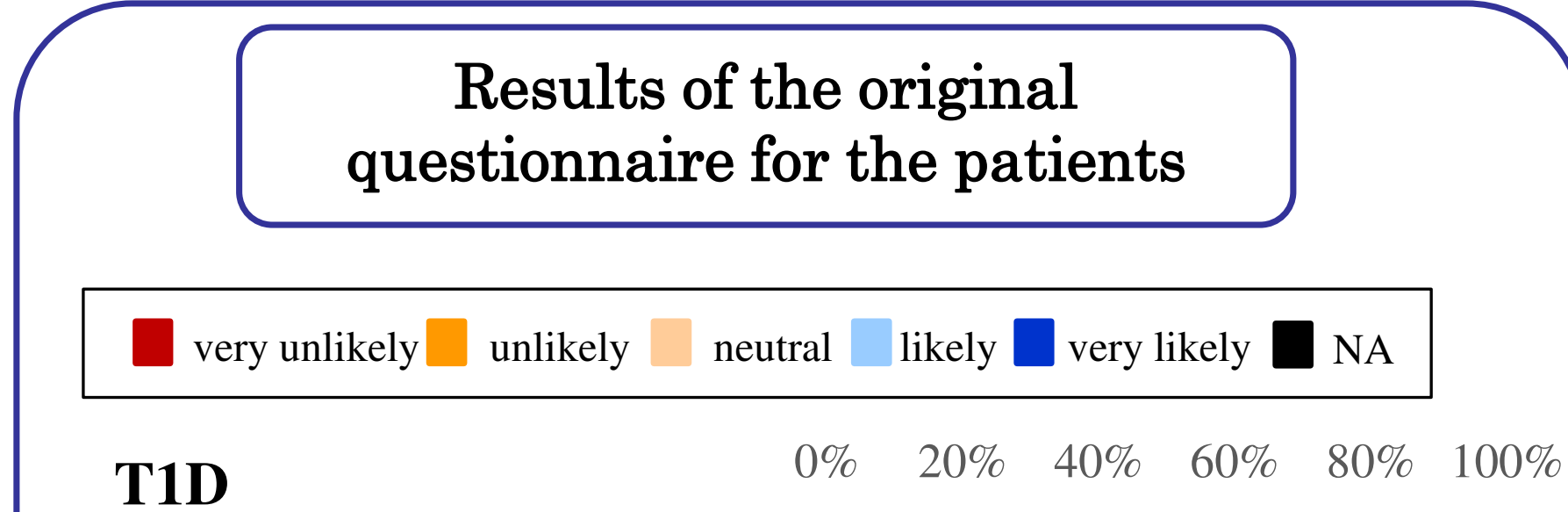

Q1) How important is SMBG to you?

Q2) How painful is SMBG to you?

Q3) How confident are you to write down SMBG results correctly?

Q4) Would you like to share your SMBG results with your physician?

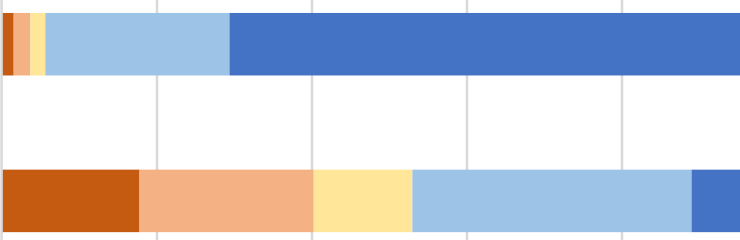

T2D

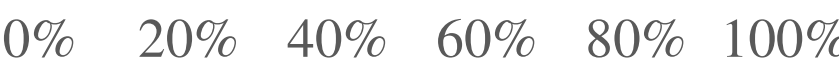

Q1) How important is SMBG to you?

Q2) How painful is SMBG to you?

Q3) How confident are you to write down SMBG results correctly?

Q4) Would you like to share your

SMBG results with your physician?
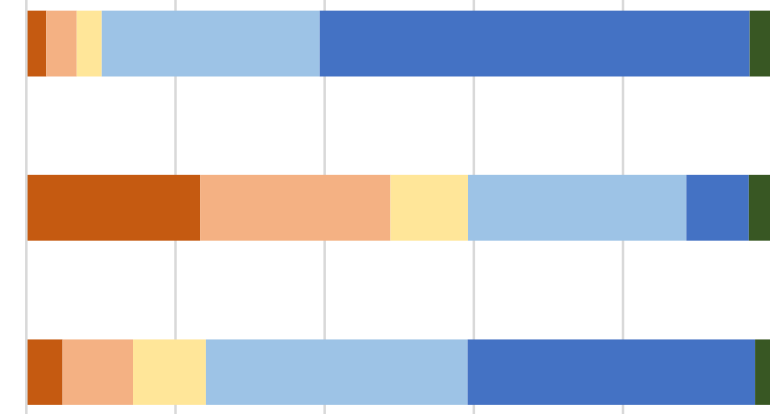

\section{.}

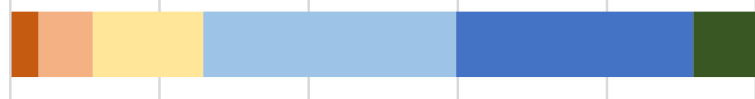

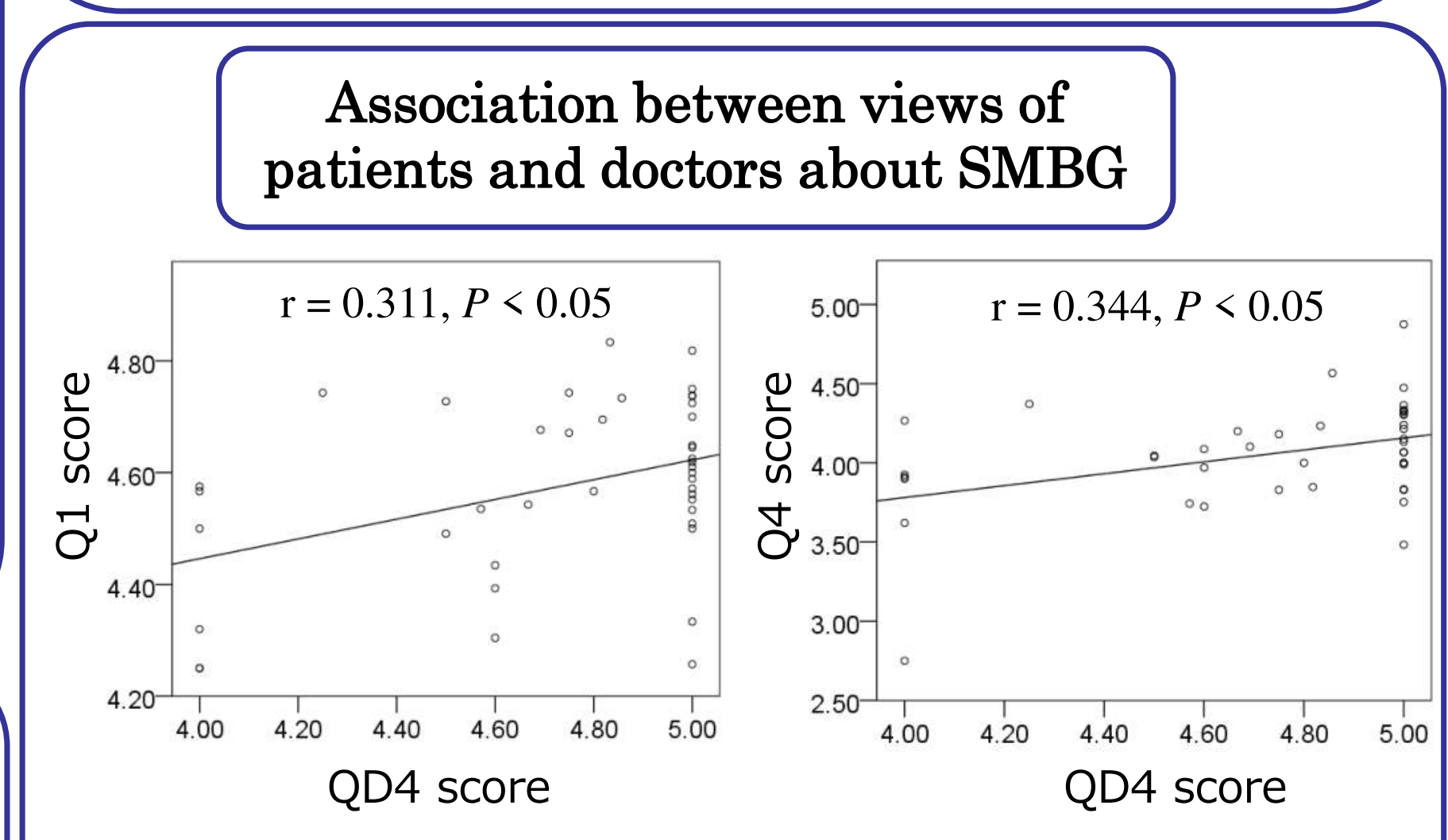

Score of QD4) "Do you check patients' SMBG diary regularly?" for doctors was significantly associated with the score of Q1 and Q4.

This study is financially supported by Terumo Corporation. 